\title{
SERUM NEOPTERIN AS A BIOMARKER FOR SILICOSIS AMONG CLAY BRICK INDUSTRY WORKERS
}

\author{
By \\ Khalifa EM ${ }^{1}$, Elsharkawy $\mathrm{SA}^{3}$, Nour $\mathrm{ZA}^{2}$, Ashour $\mathrm{SS}^{2}$ and Shehata $\mathrm{RS}^{1}$ \\ ${ }^{1}$ Department of Occupational and Environmental Medicine, ${ }^{2}$ Department of Medical Biochemistry \\ and Molecular Biology, Faculty of Medicine, Cairo University, ${ }^{3}$ Department of Community and \\ Occupational Medicine, Faculty of Medicine, Al-Azhar University, Cairo, Egypt.
}

Corresponding author: Shehata RS.Email: rehab.shehata@kasralainy.edu.eg

DOI: 10.21608/ejom.2021.91213.1248

Submit date: 2021-08-19 Revise date: 2021-09-12 Accept date: 2021-09-22

Authors' contribution: Shehata RS and Khalifa EM : study design, data collection and editing the manuscript., Elsharkawy SA :statistical analysis, Nour ZA and Ashour SS : laboratory investigations.

\begin{abstract}
Introduction: Brick industry workers are exposed to silica dust and they are at risk of developing silicosis. Serum Neopterin is used as indicative of a pro-inflammatory immune status and it could be used as a biological marker for diagnosis of silicosis Aim of Work: To assess the environmental exposure for silica at clay brick industry and evaluate the use of serum Neopterin as an early biomarker for silicosis among silica exposed workers. Materials and Methods: A cross-section study was done on 118 individuals; 58 exposed to silica ( 28 workers of them were diagnosed to have silicosis) and 60 unexposed workers were used as control. The studied group was subjected to a questionnaire, clinical examination, spirometry, chest radiograph, serum Neopterin, and environmental measurements. Results: Mean values of environmental free crystalline and respirable silica were higher than the national and international permissible levels. Significantly deteriorated spirometry measurements were observed among exposed workers mostly among the silicotic group. The serum Neopterin median was significantly higher among the silicotic group $(23.8 \mathrm{~nm} \backslash \mathrm{l})$ than the non-silicotic exposed $(12.1 \mathrm{~nm} \backslash \mathrm{l})$ and control groups $(3.6 \mathrm{~nm} \backslash \mathrm{l})$. There were significant positive correlations of Neopterin level with the silica exposure $(r=0.9)$, the work duration $(r$ $=0.8)$, and radiographic findings $(\mathrm{r}=0.7)$. Monitoring of serum Neopterin showed its good diagnostic capacity with cutoff value $17 \mathrm{~nm} / \mathrm{L}$ (The area under the curve was 0.88 ), with sensitivity, $86 \%$ and specificity of $87 \%$. Conclusion: The current study results support the use of serum Neopterin as an early biomarker for silicosis screening among
\end{abstract}


silica exposed workers in early stages before developing fibrosis.

Keywords: Brick industry; Silicosis; Free crystalline silica; Neopterin and early biomarker.

\section{Introduction}

A high level of crystalline silica (CS) is occupationally produced during all industrial processes of brick manufacturing (Sanjel et al., 2018). Silica is a naturally occurring and abundant mineral that constituted over $95 \%$ of the earth's crust and is the basic element of the majority of rocks as granite rock, sand, soil, and quartz rock (Barnes et al., 2019). It represents about 50-60\% of the clay brick (Zawilla et al., 2014). The brick manufacturing industry is one of the oldest and biggest industries in Egypt, about 1 million workers are employed in this industry (Kalliny and Bassyouni, 2011).

Crystalline silica is a well-known respiratory risk and it is associated with the development of respiratory diseases like silicosis, pulmonary tuberculosis, and chronic obstructive pulmonary disease (COPD). It is also associated with other adverse health effects as silica nephrotoxicity and autoimmune diseases particularly scleroderma and rheumatoid arthritis (Ghahramani, 2010 and Barnes et al., 2019). Moreover, The International Agency for Research on
Cancer (IARC) classified crystalline silica as a "Group 1" human carcinogen (IARC, 2012).

Silicosis is one of the oldest occupational diseases worldwide and it is a leading cause of death of occupationally exposed workers (WHO, 2007). The development of silicosis is influenced by the dose and the duration of silica exposure. When the fine respirable silica particles of an aerodynamic diameter of 0.5 to 5 microns are inhaled, alveolar macrophages uptake inhaled silica and become activated (Cheepsattayakorn and Cheepsattayakorn, 2018). The activated macrophages are the first line cells that interact with inhaled silica and play a very important role in the development of silicosis. They release inflammatory mediators and chemotactic factors that trigger cellular responses of the leukocytes and lymphocytes which in turn release several pro-inflammatory cytokines and chemokines as (interleukin-1 (IL-1), tumor necrosis factor- $\alpha$ (TNF- $\alpha$ ), neopterin, leukotrienes) that initiate series of inflammatory reactions that induce the development of pulmonary fibrosis (Mohammadi et al., 2018). 
Neopterin is a low molecular mass substance that belongs to a group of heterogeneous compounds called pteridines. It is biosynthesized from guanosine triphosphate (GTP) that is produced by activated macrophages and dendritic cells after stimulation by lymphokine called interferon-gamma that is enhanced by tumor necrosis factor following activation of $\mathrm{T}$ lymphocytes. (Steven et al.,2018).

Neopterin level reflects activation of cellular immune response that is involved in the pathogenesis of various diseases and it serves as a biomarker of cell-mediated immunity (Prasanna et al., 2017). Its concentration in biological fluids as serum, urine, and sputum may be helpful in the diagnosis of various inflammatory and immunemediated diseases (Molero-Luis et al. 2013). Different studies have shown significantly elevated Neopterin levels in patients with infections, immunerelated diseases, and tumors (Melichar et al., 2017). Some studies evaluate the level of Neopterin among silica exposed workers and investigate its use as a biological marker for early detection of silicosis (Mohammadi et al., 2018).

Silicosis is a progressive, irreversible and fibrotic lung disease and is usu- ally diagnosed at late progressive stages (Barnes et al., 2019).

\section{Aim of Work}

To assess the environmental exposure for silica at clay brick industry and evaluate the use of serum Neopterin as an early biomarker for silicosis among silica exposed workers

\section{Material and Methods}

Study design: It is a comparative cross-sectional study

Place and duration of the study: The study was performed at a clay brick factory at Helwan, Cairo, Egypt. It was done from May to December 2017.

Study sample: The total number of workers at the factory was 130 . The studied group consisted of 118 male workers. They were classified into two groups:

- Exposed group is composed of 58 male workers $(44.6 \%$ of the factory workers) who fulfill the inclusion criteria (employed in the clay brick factory and exposed to silica dust for at least two years). The exposed group was further subdivided into silicotic and non-silicotic groups according to the following diagnostic criteria of silicosis: (Fernández Álvarez et al., 2015) 
A- Occupational history of silica dust exposure.

B- Radiographic evidence of pneumoconiosis (ILO classification guidelines) (ILO, 2011).

C- Exclusion of other possible diseases and differential diagnosis.

D- Pulmonary function tests: these are considered complementary tests that help in diagnosis, assessment of severity, and follow-up.

The rest of the workers were excluded from the study according to the exclusion criteria that included any worker with a disease that may raise the Neopterin level as autoimmune disease (rheumatoid arthritis, systemic lupus), cardiovascular disease (coronary heart disease, cardiomyopathy), viral hepatitis, human immunodeficiency virus (HIV), inflammatory disease of the gastrointestinal tract (ulcerative colitis and Crohn's disease), neuropsychiatric abnormalities, history of pulmonary tuberculosis, malignancy and obese workers $\left(\mathrm{BMI} \geq 30 \mathrm{Kg} / \mathrm{m}^{2}\right)$.

- Unexposed group: The other group is a comparative one consisted of 60 matching male participants recruited from administrative workers with no previous history of occupational exposure to silica dust and they did not live near to silica industrial area.

Study Methods: Both groups were subjected to the following:

1- Predesigned questionnaire including personal history (age, marital status, number of children, smoking habits), occupational history (duration of employment, working hours, nature of the work and previous job), and full medical history.

2- Clinical examination with special emphasis on chest manifestations. It included (progressive exertional dyspnea, expectoration, hemoptysis, chest pain, rhonchi, vesicular breathing with prolonged expiration, and crepitation). Weight and height were measured and the Body Mass Index (BMI) was calculated according to the formula: weight $(\mathrm{kg}) /[\text { height }(\mathrm{m})]^{2}$

3- Spirometry: It included forced expiratory volume at the end of the first second (FEV1), forced vital capacity (FVC), and FEV1/ FVC\%.

4- Chest $x$-ray: It was performed during the annual periodic medical examination for the workers occupationally exposed to silica at this factory. Diagnosis of silicosis was established by the Occupational Diseases Committee, 
Health insurance Agency where chest $\mathrm{x}$-ray and pulmonary function tests were performed. At this stage, the exposed workers in the study were classified into silicotic and non-silicotic according to their chest x-ray findings of silicosis.

\section{5- Sample collection and analysis} of Human Neopterin: A sample of 5 $\mathrm{ml}$ venous blood was withdrawn from each subject. The blood was collected into sterile tubes with no anticoagulant and left to stand for 30 minutes at room temperature, centrifuged for $20 \mathrm{~min}$ utes, and then stored at $-80^{\circ} \mathrm{c}$ until the time of assay. The Human Neopterin was measured by a commercial ELISA kit (Human Neopterin ELISA Kit (NEOP), Bioassay Technology Laboratory, Shanghai, China). The ELISA was performed according to the manufacture's written instructions.

6- Environmental measurement: A preliminary visit was done to inspect the workplace for proper environmental evaluation and assessment.

Air sampling of total suspended particulate matter (TSP):

Total suspended particulates matter (TSP) were measured in air through calibrated vacuum pump with a cellu- lose membrane filter which aspirates and collects air at a rate of $14 \mathrm{~L} /$ minute and for 8 hours. The pumps were placed 1.5 meters higher than the ground. The membrane filters were weighed before and after sampling and the difference of weight in between was considered the concentration of (TSP) in $\mathrm{mg} / \mathrm{m}^{3}$. Air samples were performed at six different exposure sites at the clay brick factory at different times.

\section{A sampling of respirable dust:} Samples were taken through a portable personal sampling pump which was attached to the worker's clothes at the personal breathing zone. Pump calibration was done before and after sampling, the flow rate was adjusted to be 1.7 liters/ minute for at least 8 hours through a nylon cyclone connected to a polyvinyl chloride filter of $5 \mu \mathrm{m}$ size. Filters were weighed before and after sampling, and the difference of weight in between was considered the respirable dust concentration in $\mu \mathrm{g} / \mathrm{m}^{3}$.

\section{Analysis of free silica content:}

Analysis of the collected dust samples for the determination of free silica was done by x-ray diffraction (XRD). It was expressed in $\mu \mathrm{g} / \mathrm{m} 3$. The analysis also revealed other components as $\mathrm{Al}^{2} \mathrm{O}^{3}$ (20-30\%), $\mathrm{CaO}$, and $\mathrm{Fe}^{2} \mathrm{O}^{3}(2-5 \%)$. 


\section{Consent}

An informed consent was taken from all individuals who were eligible and agreed to participate in the study.

\section{Ethical approval}

All procedures performed in this study involving human participants were following the Declaration of Helsinki, the ethical standards of the Institutional committee (General Medical Council, 2013) and strict confidentiality (General Medical Council, 2017), and following the local ethics committee of Ethical Review Committee of Occupational and Environmental Medicine Department, Faculty of Medicine, Cairo University, Egypt.

\section{Data Management}

Computer-based statistical package for social sciences (SPSS) version 16 was used. Descriptive statistics such as mean, standard deviation, median, and range were used to describe quantitative data while frequency and percentage were used for qualitative one. Analytical statistics including Chi-square, independent t-test, and analysis of variance (ANOVA) were used to assess the differences between the groups. Furthermore, because serum Neopterin concentrations among the studied workers were not normally distributed, data will be in the form of median and interquartile range and presented by box and whisker plots, in which the central box spans 25th -75 th percentiles, the middle line is the median and the whiskers extend from the minimum to the maximum concentration. Nonparametrical Kruskal -Wallis test was used to compare the differences of serum Neopterin among groups. Spearman correlation was used to determine the relationship between serum Neopterin and other variables. In addition, we used the Receiver Operating Characteristic (ROC) curve for assessment of the diagnostic value of serum Neopterin for silicosis. The area under the curve (AUC) was used to quantify the diagnostic accuracy of serum Neopterin. Youden's index J (J= sensitivity + specificity-1) was used to choose the ideal and the most appropriate cut-off value for Neopterin. P-value $\leq$ 0.05 was considered significant.

The study included 118 participants; 58 workers $(49.2 \%)$ were exposed to silica dust while 60 workers $(50.8 \%)$ were not exposed. No significant differences were observed between both exposed and control groups as regards age, body mass index, marital status, 
and smoking habit $(p>0.05)$. The mean duration of employment for the exposed workers was $21.18 \pm 9.67$ years (range 2-39 years) and their age ranged from
20 to 59 years. The prevalence of silicosis among the studied exposed workers was $48.3 \%(\mathrm{No}=28$ out of 58 studied exposed workers)

\section{Results}

Table (1): Environmental measurements of total dust, respirable dust, and free silica in the workplace.

\begin{tabular}{|l|c|c|c|c|}
\hline $\begin{array}{c}\text { Environmental } \\
\text { measurements }\end{array}$ & Minimum & Maximum & $\begin{array}{c}\text { Mean } \pm \\
\text { SD }\end{array}$ & $\begin{array}{c}\text { Recommended exposure } \\
\text { limit (REL) by the National } \\
\text { Institute for Occupational } \\
\text { Safety and Health (NIOSH) }\end{array}$ \\
\hline $\begin{array}{l}\text { Total suspended particulate (TSP) } \\
\left(\mathrm{mg} / \mathrm{m}^{3}\right)\end{array}$ & 2.83 & 4.65 & $3.98 \pm 0.68$ & 10 \\
\hline Respirable dust $\left(\mathrm{mg} / \mathrm{m}^{3}\right)$ & 0.46 & 1.89 & $1.21 \pm 0.63$ & 0.1 \\
\hline Free crystalline silica $\mathrm{FCS}\left(\mu \mathrm{g} / \mathrm{m}^{3}\right)$ & 76.4 & 130 & $106 \pm 23.96$ & 50 \\
\hline
\end{tabular}

Recommended exposure limit (REL) by the National Institute for Occupational Safety and Health (NIOSH) (NIOSH, 2002)

Table (1) Environmental assessment of total, respirable and free silica dust at brick clay industry workplace revealed that the mean value of the environmental measurement of the free crystalline silica dust and respirable dust were $(106 \pm 23.96$ $\mu \mathrm{g} / \mathrm{m}^{3}$ and $\left.1.21 \pm 0.63 \mathrm{mg} \backslash \mathrm{m}^{3}\right)$ respectively, which were higher than the recommended exposure limit (REL) by the National Institute for Occupational Safety and Health (NIOSH), while the mean value of TSP was within the exposure limit).

Table (2): Spirometric parameters among the studied groups.

\begin{tabular}{|l|c|c|c|c|c|}
\hline & $\begin{array}{c}\text { Silicotic } \\
\text { No= 28 }(\mathbf{2 3 . 7 \%} \\
\text { Mean } \pm \text { SD }\end{array}$ & $\begin{array}{c}\text { Non-silicotic } \\
\text { No=30 }(\mathbf{2 5 . 4 \% )} \\
\text { Mean } \pm \text { SD }\end{array}$ & $\begin{array}{c}\text { Control } \\
\text { No= 60 (50.8\%) } \\
\text { Mean } \pm \text { SD }\end{array}$ & $\begin{array}{c}\text { ANOVA } \\
\text { test }\end{array}$ & p value \\
\hline FEV1 (\% predicted) & $63.14 \pm 13.7$ & $79.33 \pm 11.2$ & $84.5 \pm 7.9$ & 40.17 & $<\mathbf{0 . 0 0 1 *}$ \\
\hline FVC (\% predicted) & $67.9 \pm 10.7$ & $84.3 \pm 6.9$ & $89.7 \pm 9.6$ & 52.15 & $<\mathbf{0 . 0 0 1 *}$ \\
\hline FEV1 1 FVC (\% predicted) & $77.0 \pm 9.3$ & $79.8 \pm 11.27$ & $88.0 \pm 6.5$ & 19.44 & $<\mathbf{0 . 0 0 1 *}$ \\
\hline
\end{tabular}

FEV1: Forced expiratory volume in one second;

FVC: Forced vital capacity

*: Highly statistically significant 
Table (2) showed that there was a significant decline of spirometric measurements among the exposed workers compared to the controls. The predicted percentage of spirometric parameters (FEV1, FVC, and FEV1/ FVC) were significantly lower among the silicotic group $(63.14 \pm 13.7,67.9 \pm 10.7$ and $77.0 \pm 9.3$ respectively) compared to the non- silicotic $(79.33 \pm 11.2,84.3 \pm 6.9$ and $79.8 \pm 11.27)$ and the control groups $(84.5 \pm 7.9,89.7 \pm 9.6$ and $88.0 \pm 6.5)$.

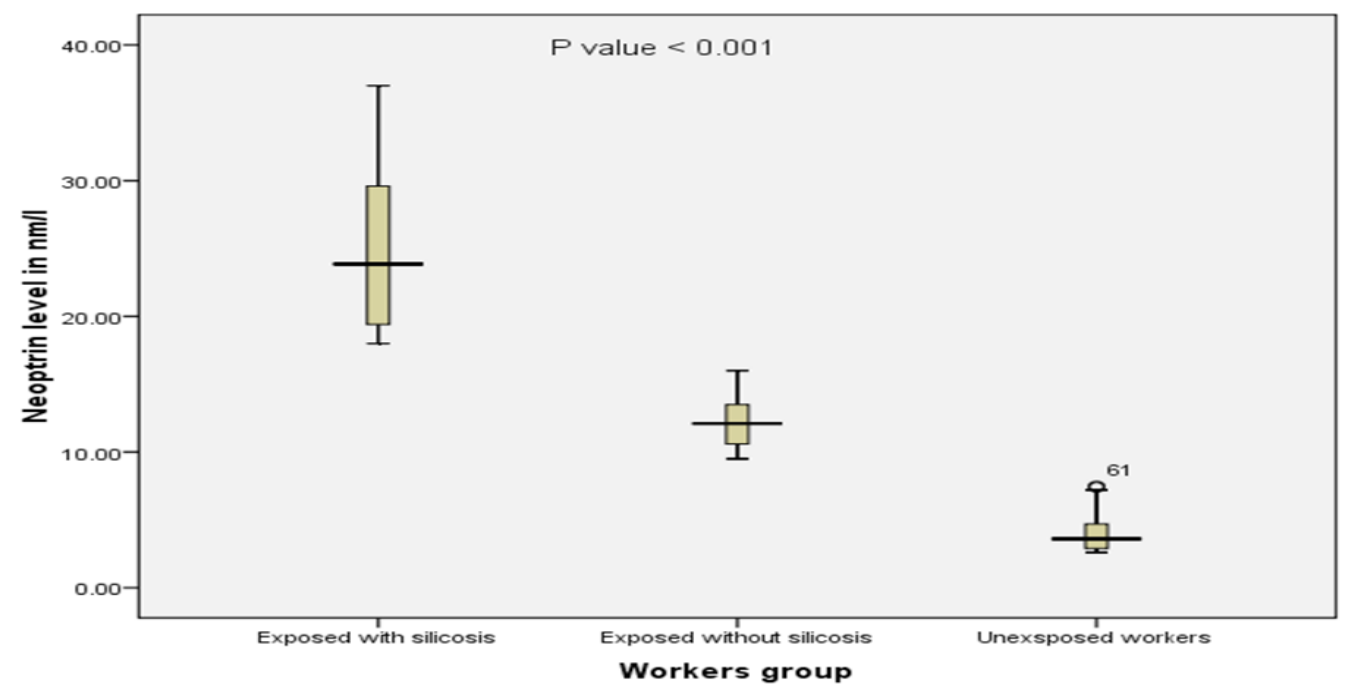

Figure (1): Box plot for Neopterin level among the studied groups of workers

Fig. (1) revealed that there was a statistically significant difference in serum Neopterin level among the studied groups. The median and interquartile range of serum Neopterin were the highest among the silicotic group (23.8, 19.4- 29.7) respectively. Also, it was significantly higher among the non-silicotic exposed group $(12.1,10.5-13.5)$ compared to the unexposed group (3.6, $2.9-4.7)$ (p-value $<0.001)$ by using non-parametric tests (Kruskal Wallis test) as the serum Neopterin was not normally distributed. 
Table (3): Correlation between Neopterin level and different affecting variables

\begin{tabular}{|l|c|c|}
\hline \multicolumn{1}{|c|}{ Variables } & Correlation coefficient (r) & p value \\
\hline Age & 0.42 & $<\mathbf{0 . 0 0 1 *}$ \\
\hline Duration of work & 0.80 & $<\mathbf{0 . 0 0 1}$ * \\
\hline BMI & 0.11 & 0.90 \\
\hline FEV1 & -0.45 & $<\mathbf{0 . 0 0 1}$ * \\
\hline FVC & -0.56 & $<\mathbf{0 . 0 0 1}$ * \\
\hline FEV1/FVC & -0.41 & $<\mathbf{0 . 0 0 1 *}$ \\
\hline X-Ray opacities & 0.74 & $<\mathbf{0 . 0 0 1 *}$ \\
\hline Smoking index & 0.11 & 0.20 \\
\hline Exposure to silica & 0.91 & $<\mathbf{0 . 0 0 1 *}$ \\
\hline
\end{tabular}

FEV1: Forced expiratory volume in one second;

*:Highly statistically significant

BMI:Body Mass Index

FVC: Forced vital capacity

Table (3) showed that there was a statistically significant strong positive correlation of Neopterin level with the exposure to silica $(r=0.9)$, the duration of work $(\mathrm{r}=0.8)$, clinical finding on $\mathrm{x}$-ray $(\mathrm{r}=0.7)$, and with the age $(\mathrm{r}=0.4)$. Also there was statistically significant negative correlation of Neopterin level with the predicted percentage FEV1 $(\mathrm{r}=-0.45)$, FVC $(\mathrm{r}=-0.51)$ and FEV1/FVC $(\mathrm{r}=-0.41)$. There was no significant relation of Neopterin level with the body mass index and smoking index.

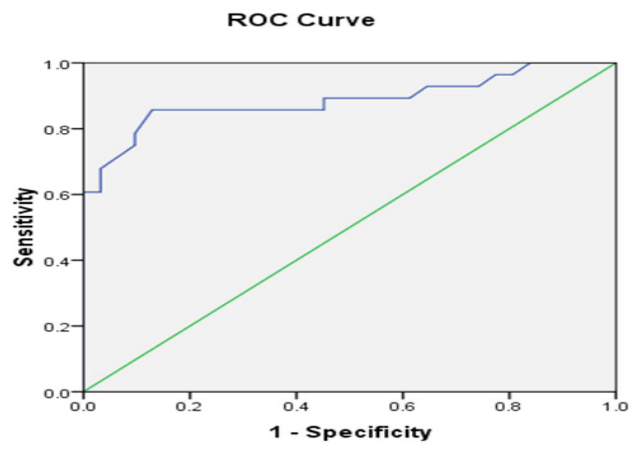

Figure (2) Receiver Operating Characteristic (ROC) for Neopterin cutoff point, sensitivity, and specificity in the diagnosis of silicosis

Fig. (2) From the ROC curve, the area under the curve (AUC) for Neopterin level in the detection of silicosis was 0.88 (good test). The cut-off point for discrimination between the silicotic group and non-silicotic group was $17 \mathrm{~nm} / \mathrm{L}$ at which sensitivity $=86 \%$ and specificity was $87 \%$. 


\section{Discussion}

Brick manufacturing is considered to be a dusty industry, where workers are exposed to considerable amounts of silica dust and smoke during the industrial process that includes grinding and crushing of raw materials, mixing, casting, cutting, firing of the green bricks, carrying and transporting brick (Shaikh et al., 2012). The current results showed that the mean values of the free crystalline silica dust and respirable dust were $106 \pm 23.96 \mu \mathrm{g} / \mathrm{m}^{3}, 1.21 \pm 0.63 \mathrm{mg} \backslash$ $\mathrm{m}^{3}$ respectively which were higher than the permissible level of The Egyptian Environmental Law 4 Decree 1095 of 2011 for free silica $(50 \mu \mathrm{g} \mathrm{g} / \mathrm{m} 3)$ (Ministry of Environment Egyptian Environmental Affairs Agency, 2011), the recommended exposure limit (REL) by the National Institute for Occupational Safety and Health (NIOSH) $\left(50 \mu \mathrm{g} g / \mathrm{m}^{3}=0.05 \mathrm{mg} /\right.$ $\left.\mathrm{m}^{3}\right)$ for free silica and $\left(0.1 \mathrm{mg} \backslash \mathrm{m}^{3}\right)$ for respirable dust (NIOSH, 2002) and, also higher than threshold limit value (TLV) of American Conference of Governmental Industrial Hygienists (ACGIH) $\left(25 \mu \mathrm{g} / \mathrm{m}^{r}=0.025 \mathrm{mg} / \mathrm{m}^{3}\right)$ for free silica and $\left(0.1 \mathrm{mg} \backslash \mathrm{m}^{3}\right)$ for respirable dust (ACGIH, 2011) (Table 1). These findings indicated that workers in the brick industry are at a high risk of developing silica-related disorders. While the mean value of TSP (Total suspended particulate) was within the Egyptian permissible level and NIOSH (REL) of $10 \mathrm{mg} / \mathrm{m}^{3}$ (NIOSH, 2002 and Ministry of Environment Egyptian Environmental Affairs Agency, 2011)

Similar findings were detected by Zawilla et al. (2014) who studied the effect of silica exposure on liver functions among Egyptian workers in the clay brick industry. They performed an environmental measurement at two areas at the factory, the production, and the mining area and they found that the mean levels of TSP and respirable dust were within the national and international limits while the mean level of free CS (Crystalline Silica) was approximately triple than the permissible levels $(140.4 \pm 57.01$ and 165.8 \pm 79.8$)$. Similarly, a recent study in Nepal was performed among clay brick workers, the workplace measurements of free CS were of high concentrations at different sites but especially higher at the area of carrying red brick and stacking of green brick $\left(331 \mu \mathrm{g} / \mathrm{m}^{3}\right.$ and $223 \mu \mathrm{g} / \mathrm{m}^{3}$ ) respectively (Sanjel et al.,2018).

Exposure to inhaled respirable 
crystalline silica can lead to silicosis, silica-related respiratory diseases, and impaired lung functions. Based on the diagnostic criteria of silicosis which depends on the presence of clinical manifestations, history of occupational exposure to silica dust, and characteristic radiological chest findings (Deslauriers and Redlich, 2018), the exposed studied workers were classified into silicotic and non-silicotic groups. It was found that the prevalence of silicosis was $48.3 \%$ of the silica-exposed workers .These findings were in agreement with a study done by Zawilla et al., 2014; that reported that silicosis was detected among $41.3 \%$ of the silica-exposed workers in the brick industry.

Spirometry is a useful tool for determining disease severity and for follows up, but it is not a helpful tool for diagnosis of silicosis, as pulmonary functions parameters may be normal especially at the early stage of silicosis, or it may show either obstruction or restriction due to other medical causes (Fernández Álvarez et al., 2015).

Significant deteriorated spirometric measurements were observed among the studied exposed workers compared to the controls. The predicted percentage of spirometric parameters (FEV1, FVC, and FEV1/ FVC) were significantly lower among the workers with silicosis $(63.14 \pm 13.7,67.9 \pm 10.7$ and $77.0 \pm$ 9.3 respectively) and exposed workers without silicosis $(79.33 \pm 11.2,84.3 \pm$ 6.9 and $79.8 \pm 11.27)$ than the control group $(84.5 \pm 7.9,89.7 \pm 9.6$ and $88.0 \pm 6.5$ ) (Table 2). These findings were in resemblance to the results of a study that reported a decline in pulmonary functions parameters; FEV1 $\%$, predicted, FVC $\%$, and predicted FEV1 / FVC \% were $(60.84 \pm 26.18$, $66.26 \pm 24.35, \quad$ and $\quad 84.88 \pm 1.09$ respectively) among workers with silicosis in the denim sandblasting industry (Palabiyik et al., 2013).

The current study showed that the median and interquartile range of serum neopterin were the highest among the silicotic group (23.8, 19.4- 29.7). Also, it was significantly higher among the non-silicotic group $(12.1,10.5-13.5)$ compared to the unexposed $(3.6,2.9$ - 4.7) (p-value <0.001) (Fig.1). These findings were consistent with the work done by Palabiyik and his colleagues (2013) that identified a higher level of Neopterin in the biological fluids among silica exposed workers with silicosis compared to the controls. Moreover, they found that Neopterin 
levels increased concerning the severity of silicosis and they proposed the use of Neopterin as a biomarker of silicosis.

As regards the relation of serum Neopterin with other characteristics, the present study showed that there was a statistically significant strong positive correlation of Neopterin level with the exposure to silica $(r=0.9)$, the duration of work $(\mathrm{r}=0.8)$, $\mathrm{x}$-ray changes $(\mathrm{r}=0.7)$. Also there was a statistically significant negative correlation of Neopterin with the predicted percentage FEV1 ( $\mathrm{r}=$ $0.45), \mathrm{FVC}(\mathrm{r}=-0.51)$ and FEV1/FVC $(r=-0.41)$ (Table 3).

These findings were in agreement with that of Prakova et al. (2009) who found that serum Neopterin level was higher among coal mine workers who were exposed to free CS than controls and they concluded that exposure to free CS is associated with activation of cellular immunity and particularly macrophages.

There is a close relationship between the development of silicosis and the occupational accumulated exposure to CS among workers that activate the immune system. Accumulated exposure depends on the percentage of free silica in $\mathrm{mg} / \mathrm{m}^{3}$ and years of exposure (Fernández Álvarez et al., 2015).
This fact is one of the most important explanations to our current study results where clay brick workers were exposed to free CS level double the permissible level and had a mean duration of exposure to CS of years was $(21.18 \pm$ 9.67 years). So the theory of immune system stimulation after prolonged exposure was highly suspected. These results were similar to the findings of a previous study done by Mohammadi, et al. 2016 in their study on evaluation of serum and urinary Neopterin levels as a biomarker for occupational exposure to crystalline silica in Iran and detected a statistically significant positive correlation between the duration of exposure to silica and both serum and urinary Neopterin level. On other hand, another study was done by Prakova et al. 2009 in Bolgaria on serum Neopterin among workers exposed to inorganic dust containing free crystalline silicon dioxide and noticed high Neopterin concentration among workers with less than 10 years of silica exposure. The authors explained their findings by the possibility of increased immune system activation and macrophage functions during early years of exposure and then physiological adaptation occurs after longer periods exceeding 10 years. 
As regards the radiological findings and serum Neopterin level, the current study indicated that serum Neopterin level was increased in relation to the radiological finding of opacities and fibrosis due to the presence of silicosis (Table 3). These results agreed with a study done by of Prakova et al. (2009) who detected a parallel increase in serum Neopterin according to the severity of opacities in x-ray among silicotic patients and supported the use of Neopterin level in the diagnosis of silicosis beside characteristic radiographic findings.

Pulmonary function tests are helpful in clinical evaluation and assessment of disease severity (Fernández Álvarez et al., 2015). The more decline in lung volumes of FVC and FEV1, the more the magnitude of exposure and extent of x-ray findings (Hochgatterer et al., 2013). So it is logical as in this study that there was a statistically significant negative correlation of Neopterin level with the predicted percentage FEV1, FVC, and FEV1/FVC (Table 3).

The current work found no statistically significant correlation of Neopterin level with the body mass index (BMI) and smoking index (Table 3 ). These were in partial similarity to that of Prakova et al. (2009) who found higher Neopterin levels in non-smoker than smoking workers in a surface coal mine, but this difference was not statistically significant. Some studies revealed that Neopterin showed a positive association with BMI (Spencer et al., 2010). However, the presence of a non-significant correlation of Neopterin with BMI in the current study may be attributed to the exclusion of obese workers with $\mathrm{BMI} \geq 30 \mathrm{Kg} / \mathrm{m}^{2}$ to avoid the confounding effect.

The objective of this study is to evaluate the diagnostic value of serum Neopterin. For this aim, we performed a ROC curve which indicated good diagnostic capacity of serum Neopterin (The AUC was 0.88 ), with a sensitivity of $86 \%$ and specificity of $87 \%$ at value $17 \mathrm{~nm} / \mathrm{L}$ in discriminating silicotic workers from non-silicotic workers (Fig 2).

Conclusion: the present study revealed a high prevalence of silicosis among clay brick industry workers. Serum Neopterin was significantly higher among silicotic group compared to non-silicotic exposed workers and control groups and support the use of serum Neopterin as a biomarker for diagnosis of silicosis with good 
diagnostic capacity. Further researches on a large scale and other industrial activities that include exposure to silica are needed.

\section{Recommendations:Environmental} monitoring is critical to ensure the effectiveness of control measures and adherence to regulated exposure limits. Health surveillance for the exposed workers is essential for early detection and removal from further exposure (Deslauriers and Redlich, 2018). These preventive measures should be supported in the clay brick industry and everywhere where exposure to crystalline silica is suspected to reduce the prevalence of silicosis. The current work also recommends the use of serum Neopterin as biological monitoring for workers exposed to silica during periodic health surveillance for prevention of the development of silicosis.

\section{Funding}

None, the authors themselves were the research funder.

\section{Conflict of interest}

None declared

\section{Acknowledgment}

The authors would like to acknowledge all workers participated in the study for their cooperation and help.

\section{References}

1. American Conference of Governmental Industrial Hygienists (ACGIH) (2011): Threshold limit values for chemical substances and physical agents and biological exposure indices. Cincinnati, OH: ACGIH; 2011. Available at https://www.acgih.org/science/tlvbei-guidelines

2. Barnes H, Goh NSL, Leong TL and Hoy R (2019): Silica-associated lung disease: An old-world exposure in modern industries. Respirology; 24(12):1165-75.

3. Cheepsattayakorn $\mathrm{A}$ and Cheepsattayakorn $\mathrm{R}$ (2018): Silicosis: Pathogenesis and Biomarkers. Ann Clin Pathol;6(5): 1147.

4. Deslauriers JR and Redlich CA (2018): Silica Exposure, Silicosis, and the New Occupational Safety and Health Administration Silica Standard. What Pulmonologists Need to Know. Ann Am Thorac Soc; 15(12):1391-1392. DOI:10.1513/AnnalsATS.201809-589ED.

5. Fernández Álvarez R, Martínez González C, Quero Martínez A, Blanco Pérez JJ, Carazo Fernández L et al. (2015): Guidelines for the diagnosis and monitoring of silicosis. Arch Bronconeumol; 51(2):86-93. DOI: 10.1016/j. arbres.2014.07.010.

6. Ghahramani N (2010): Silica nephropathy: a review. Int J Occup Environ Health; 1:108-115.

7. Hochgatterer K, Moshammer H and Haluza D (2013): Dust is in the air: effects of occupational exposure to mineral dust on lung function in a 9-year study. Lung; 191: 257-63. DOI: 10.1007/ s00408-013-9463-7.

8. International Agency for the Research on Cancer (IARC) (2012): A review of human carcinogens: arsenic, metals, fibers, and dust. IARC Monogr Eval Carcinog Risks Hum; 100: 355-97.

9. International Labor Office (ILO) (2011): Guidelines for the use of the ILO international 
classification of radiographs of pneumoconioses. Occupational safety and health Series; No. 22 (ISBN 978-92-2-124542-1). Geneva: International Labour Office. Revised edition 2011. Available at: http://www.ilo.org/safework/ info/publications/WCMS_168260/lang - en/ index.htm (cited June 2020).

10. Kalliny $M$ and Bassyouni M (2011): Immune response due to silica exposure in Egyptian phosphate mines. J Health Care Poor Underserved; 22(4):91-109.

11. Melichar B, Spisarová $M$, Bartoušková $M$, Krčmová LK, Javorská L, et al. (2017): Neopterin as a biomarker of immune response in cancer patients. Ann Transl Med; 5 (13):280. DOI: 10.21037/atm.2017.06.29.

12. Ministry of Environment Egyptian Environmental Affairs Agency (2011): Egyptian Environmental Law 4 Decree 1095. Official Gazette No. 199; 2011. pp. 110-112 (for dust). Available at: https://www.eeaa.gov.eg/en-us/ laws/envlaw.aspx

13. Mohammadi H, Dehghan SF, Golbabaei F, Ansari M, Yaseri M et al. (2016): Evaluation of serum and urinary neopterin levels as a biomarker for occupational exposure to crystalline silica. Ann Med Health Sci Res; 6 (5): 274-9.

14. Mohammadi H, Farhang D S, Tahamtan A, and Golbabaei F (2018): Evaluation of potential biomarkers of exposure to crystalline silica: A case study in an insulator manufacturer. Toxicol Ind Health; 34(7): 491-8. DOI: 10.1177/0748233718770073

15. Molero-Luis M, Fernández-Ureña S, Jordán I, Serrano M, Ormazábal A, et al. (2013): Cerebrospinal fluid neopterin analysis in neuropediatric patients: establishment of a new cut-off-value for the identification of inflammatory-immune mediated processes. PLoS One; 8(12): e83237. DOI:10.1371/ journal.pone. 0083237 .

16. National Institute for Occupational Safety and Health (NIOSH) (2002): NIOSH Hazard
Review: Health effects of occupational exposure to respirable crystalline silica. [document on the internet] Cincinnati, OH: U.S. Department of Health and Human Services, Public Health Service, Centers for Disease Control and Prevention, National Institute for Occupational Safety and Health, DHHS (NIOSH) Publication No. 2002-129:1-127.Available at: http://www. cdc.gov/niosh/docs/2002-129/pdfs/ 2002-129. pdf (cited June 2020).

17. Palabiyik SS, Girgin G, Tutkun E, Yilmaz OH, Baydar T, et al (2013): Immunomodulation and oxidative stress in denim sandblasting workers: changes caused by silica exposure. Arh Hig Rada Toksikol; 64(3):431-437. DOI: 10.2478/10004-1254-64-2013-2312.

18. Prakova G, Gidikova P, Slavov E, Sandeva G and Stanilova S, et al. (2009): Serum neopterin in workers exposed to inorganic dust containing free crystalline silicon dioxide. Cent Eur J Med 2009; 4 (1): 104-9.

19. Prasanna JS, Sumadhura $C$ and Karunakar $P$ (2017): Neopterin as a diagnostic biomarker for diagnosis of inflammatory diseases like periodontitis. J Oral Res Rev; 9:45-9.

20. Sanjel S, Khanal SN, Thygerson SM, Carter W, Johnston JD, et al. (2018): Exposure to respirable silica among clay brick workers in Kathmandu valley, Nepal. Arch Environ Occup Health; 73(6)347-50. DOI:10.1080/19338244.2 017.1420031.

21. Shaikh S, Nafees A, Khetpal V, Jamali A, Arain A, et al. (2012): Respiratory symptoms and illnesses among brick kiln workers: a crosssectional study from rural districts of Pakistan. BMC Public Health; 12:999.

22. Spencer ME, Jain A, Matteini A, Beamer BA, Wang NY, et al. (2010): Serum Levels of the Immune Activation Marker Neopterin Change with Age and Gender and Are Modified by Race, BMI, and Percentage of Body Fat. J Gerontol A Biol Sci Med Sci; 65A (8): 858-65. DOI: $10.1093 /$ Gerona/glq066.

23. Steven G, Gregory BP and Angus L (2018): 
Neopterin, Inflammation, and Oxidative Stress: what Could We Be Missing? Antioxidants; 7(7):80. DOI:10.3390/antiox7070080

24. World health organization (WHO) (2007): Elimination of Silicosis, The Global Occupational Health Network. 2007; (12): 1-18. Available at: http://www.who.int/occupational_ health/publications/newsletter/gohnet12e.pdf (accessed June 2020).

25. Zawilla N, Taha F and Ibrahim Y (2014): Liver functions in silica-exposed workers in Egypt: possible role of matrix remodeling and immunological factors. Int $\mathrm{J}$ Occup Environ Health; 20 (2):146-56. DOI:10.1179/20493967 14Y.0000000061. 